\title{
CHARLES DAVID LEY (1913-1996): POETA Y TRADUCTOR EN LA REVISTA CÁNTICO
}

\author{
Juan de Dios Torralbo Caballero \\ Universidad Complutense de Madrid ${ }^{1}$ y Universidad de Córdoba
}

\section{Resumen}

Este trabajo se centra en el filólogo Charles David Ley (Londres, 1913-1996) con el objetivo de explorar su colaboración literaria en la revista Cántico. En primer lugar, se plantea una breve aproximación a su vida y a su obra, pues se trata de un escritor poco conocido. En segundo lugar, se investigan sus poemas escritos en inglés y publicados en la revista como es el caso de «Meditation». En tercer lugar, se estudia su labor como traductor donde destaca la traducción de dos fragmentos de John Milton (en coautoría con José García Nieto), así como de un poema de Dylan Thomas. Finalmente se profundiza en la figura de Charles David Ley como autotraductor, porque él mismo compone un poema en inglés («The Mosque-Cathedral»), que traduce a continuación. Esta prospección permite concluir una vez más el carácter internacional de la edición periódica cordobesa, promovido por el aperturista afán divulgador de sus directores y objetivado a través de los colaboradores en las diversas secciones de la publicación, como es el caso de Charles David Ley.

Palabras clave: Revista Cántico, Traducción Literaria, Autotraducción, Charles David Ley.

\section{CHARLES DAVID LEY (1913-1996): POET AND TRANSLATOR IN THE JOURNAL CÁNTICO}

\begin{abstract}
This work focuses on the philologist Charles David Ley (London, 1913-1996) with the aim of exploring his literary contributions to the Spanish journal Cántico. Firstly, a brief approach to his life and work is presented, since he is a little-known writer.
\end{abstract}

1 Adscrito al Programa de Doctorado en Lengua Española y sus Literaturas.

Fecha de recepción: 20 de febrero de 2019

Fecha de aceptación: 13 de mayo de 2019 
Secondly, his poems written in English and published in the journal are studied, as in the case of «Meditation». Thirdly, his work as a translator is considered, highlighting his translations into Spanish of two fragments by John Milton (co-authored with José García Nieto), as well as a poem by Dylan Thomas. Finally, the figure of Charles David Ley as his own translator (self-translator) is examined, as he himself composes a poem in English («The Mosque-Cathedral»), which he translates into Spanish. This examination serves to confirm and exemplify, once again, the international dimension of the Cordoban journal, a product of its editors' aspiration to expose its readers to international writers and literature, through collaborations in the various sections of the publication, such as that of Charles David Ley.

Keywords: Cántico Journal, Literary Translation, Self-translation, Charles David Ley.

\section{INTRODUCGión}

Como objetivo general, este trabajo cartografía el afán internacional del grupo «Cántico», que incorpora una galería notable de poetas extranjeros en las páginas de su revista, fundada en Córdoba en octubre de 1947. Vicente Aleixandre (2007: 35) señala la potencial fertilidad de esta publicación en febrero de 1948 cuando escribe: «Ustedes, cordobeses, en tierra honda han originado una revista. Viva y fértil puede ser».

En otros artículos (Torralbo Caballero, 2018a y 2018b) se ha investigado la presencia de literaturas foráneas en esta revista concluyéndose la heterogeneidad, el aperturismo y el dinamismo de sus directores (Ricardo Molina, Pablo García Baena y Juan Bernier), que insuflan nuevos aires en la poesía cordobesa, andaluza y española de postguerra. Ahora, en lugar de realizar un trabajo monográfico sobre todas las importaciones y adaptaciones de una lengua concreta, el objetivo específico se centra en un profesor, filólogo inglés e hispanista, cuyo nombre es Charles David Ley. Por tanto, este capítulo explora la figura de Charles David Ley y, particularmente, sus publicaciones en la revista cordobesa Cántico.

En este sentido, es memorable la nota necrológica que redacta José Ortega Ortega para El País, publicada en este periódico español el 15 de octubre de 1996. A pesar del eco periodístico que tuvo en 1996, destaca la carencia de estudios sobre el profesor y escritor, puesto que no tenemos constancia de la existencia de investigaciones al respecto. Buscando su imagen en internet, solamente nos ha sido posible hallar unas fotos grupales en la web de «Turismo de las Navas» junto a otras personalidades del momento y alguna en el Café Gijón (Ley, 1988: 183-188).

\section{Presentación del escritor}

Charles David Ley nace en Londres el 11 de marzo de 1913 y muere en la misma ciudad en el otoño de 1996. Su formación académica reglada 
consta de estudios universitarios de grado y de postgrado, destacando la realización de dos doctorados. Primero se gradúa en Lengua y Literatura Inglesa y Lenguas Modernas en la Universidad de Londres. Años más tarde, en 1954, defiende su tesis doctoral en la Universidad de Madrid bajo el título de El gracioso en el teatro de la Península. Siete años después presenta otra tesis en Londres bajo el rótulo de Poesía española a partir de 1939 que puede consultarse en forma de libro (Ley, 1962).

El mismo Ley (1952: 9) expresa en la presentación de sus Poemas para España «que conocí [España] tan solo después de haber alcanzado ya la mayoría de edad». Tras ejercer como docente en el Instituto Británico de Lisboa (1939-1943) pasa al mismo instituto de Madrid, donde enseña desde 1943 hasta 1952, organizando - entre otras actividades- «una clase de inglés para escritores» (Ley, 1981: 64) a la que asisten creadores como José García Nieto. En estas sesiones utiliza la poesía para enseñar lengua; él mismo lo declara así: «no me atreví a sacar a Shakespeare en los primeros pasos lingüísticos, aunque más tarde traté de leerles, a los pocos que quedaban, unos versos de Dylan Thomas» (Ley, 1981: 65). El siguiente puesto laboral lo desempeña en la Universidad de Salamanca, donde trabaja como lector de inglés. También imparte clases en el College of Technology de Danford, desde 1959 hasta 1978.

Charles David Ley se relaciona con los poetas españoles de la postguerra. En Madrid - sirva de ilustración al respecto-, acude a la tertulia celebrada en el Instituto Británico, organizada por Walter Starkie al tiempo que participa en las tertulias del Café Félix y del Café Gijón (Ley, 1988: 183; Spottorno, 1996).

En cuanto a su legado literario - además de sus memorias (Costanilla de los diablos) — destaca su trabajo Shakespeare para españoles (1951), difundido en la Revista de Occidente y posteriormente también en formato de libro monográfico. Al filólogo londinense debemos la traducción de la Historia de Cardenio — de Shakespeare y Fletcher-.

La labor investigadora de Charles David Ley también incluye estudios sobre la literatura portuguesa como Portuguese Voyages 1498-1663 (Ley, 1947), La moderna poesía portuguesa (Ley, 1951) o algunas traducciones de Pío Baroja. Además, realiza trabajos sobre poesía española contemporánea (Ley, 1967: 377-385), Lope de Vega (Ley, 1977: 579-585) o la influencia de Pablo Neruda en la poesía moderna española (Ley, 1970: 543-552). Su valor intercultural, que se aprecia leyendo las colaboraciones en las revistas Garcilaso o Cántico, ha sido mencionada por José-Carlos Mainer (2005: 2), quien lo define como «el lugarteniente de Walter Starkie en el British Institute en sus breves memorias [...]». 
Hemos constatado que Charles David Ley y Ricardo Molina se conocían. Así lo atestigua una entrevista realizada por el inglés para su investigación de postgrado en la que destacamos la pregunta cuarta, «What foreign poets do you consider important?» (Ley, 1962: 201), que Ricardo Molina responde reafirmando su estima por la literatura de otros países así: «Tan importante para mí como la española. Dante» (Ley, 1962: 211).

La presencia de escritores invitados - como Vicente Aleixandre (131) Leopoldo de Luis (374), Concha Lagos (428) o Marià Manent (153) — engrandece el rigor de la revista (Blanco Outón, 1994: 97). Los poetas cordobeses enriquecen de esta manera sus páginas, mediante escritores experimentados en las lides de la crítica o de la traducción literarias como es el caso de Charles David Ley, cuya formación lingüística bilingüe le permite no solamente escribir poesía en español o en inglés, sino también traducir de forma bidireccional ${ }^{3}$.

\section{Poeta en lengua inglesa}

La primera inclusión de Charles David Ley en la revista Cántico se encuentra en la última entrega de la primera época (número 8, diciembre de 1948 y enero de 1949) donde participa como colaborador. Este número, en lo que atañe a traducciones, contiene el poema del londinense en versión bilingüe, cuatro poemas catalanes (traducidos por Alfonso Pintó) solamente impresos en español (de Joan Vinyoli incluye «Al retrato de una muchacha»; de Joan Triadú, «Miro el callado porvenir»; de Josep Palau, «Amarga memoria» y de Joan Perucho, "Arena del amor») junto a las cinco partes del poema de T.S. Eliot titulado «The Hollow Men», traducido por José Antonio Muñoz Rojas, igualmente solo en versión monolingüe.

El poema de Charles David Ley es «Meditation» y la traducción en este caso es obra de la profesora cordobesa Carmen Fustegueras. Ambas versiones fueron diseñadas en paralelo, por lo que el lector puede comparar el binomio textual fácilmente:

There the great ships go sailing out beyond Leaving my sorrows here

Where I stand sadly by the wintry pond.

The flights of swallows sweep across the sky

Yet I would linger on

Till Time and Men and Fortune have moved by.

2 Citamos las páginas por Cántico. Hojas de poesía, 1947-1957, Córdoba, Diputación Provincial de Córdoba-Consejería de Cultura de la Junta de Andalucía-Fundación Cajasur, 2007.

3 Un ejemplo de esta faceta es su traducción al inglés de la poesía de Rosalía de Castro (1964). 
The nearby traffic on a Southern sea

Sends its cries up the hill

And all those cries are emptiness to me.

Only these waters in this little park

Ripple as dusk comes down

And distant lights begin to star the dark.

Allá van las grandes naves bogando hacia lugares lejanos

dejando mis tristezas aquí

donde yo quedo, junto al estanque invernal, sumido en mi dolor.

El vuelo de las golondrinas surca majestuosamente el palacio

mas yo quisiera seguir deteniéndome

hasta que el Tiempo, los Hombres y el Destino hayan de vacilar.

El tráfico cercano de un mar del Sur

emite su vocerío que asciende hasta la montaña

y todos estos gritos son para mí mera vanidad.

Sólo las aguas de este pequeño parque

ondean sus reflejos cuando el crepúsculo desciende

y las luces lejanas empiezan a llenar de estrellas las tinieblas (122).

Esta pieza meditativa donde se nombra la «tristeza» aviene al pensamiento de la traductora que vivió vicisitudes personales en la Guerra Civil con el fusilamiento de su marido, Aurelio Pérez Cantero (en 1936) y con la denuncia contra ella por pertenecer a la Federación de Trabajadores de la Enseñanza. Es época de penalidades y de hambre en la ciudad, que Gerald Brenan (1952: 42-43) las refleja así en 1950: «No es posible andar por Córdoba sin sentirse horrorizado ante tanta miseria [...] Lo más impresionante son los que se arrastran por las calles sin brazos ni piernas.». Durante el comienzo de la dictadura «la otrora esplendorosa capital omeya se ve sumida en una pobreza incalculable, pobreza que provoca enormes dificultades a gran parte de la población, que debe sobrevivir entre hambre y ruina, racionamiento y enfermedad, suciedad y escombro» (Martín Puya y Moreno Díaz, 2013: 59).

\section{Dos fragmentos de John Milton traducidos con José García Nieto}

Charles David Ley y José García Nieto — fundador de la revista Garsilasoson los traductores de dos fragmentos de la tragedia de John Milton (1671), publicados en el número sexto de la segunda época, en febrero-marzo de 1955.

La amistad de ambos literatos viene de antes, como revela, por ejemplo, la estancia que pasaron en Las Navas, invitados por Camilo José Cela, concretamente en agosto de 1944. Los momentos estivales vividos junto a Cela 
están literaturizados por José García Nieto en el poema titulado «Las Navas del Marqués». Otra muestra de su relación amical es la participación de García Nieto en la representación de una tragedia irlandesa, dirigida por Ley, en el Instituto Británico, hacia 1945. En noviembre de ese mismo año, Ley asiste a la representación «de un auto poético» que García Nieto estrena en el Teatro Español (Ley, 1981: 64). Además —ya se ha mencionado- el escritor ovetense asiste a las clases de inglés que Ley imparte en el Instituto Británico de Madrid.

El primer extracto traducido figura en la página primera de la revista bajo la cabecera, se titula «Sansón lamenta su ceguera» (271) y viene solamente en español. Su temática, de tintes negativos y aureola pesimista, dialoga con el momento histórico que vive España, engarzando así con el panorama antes mencionado de postguerra. Al mismo tiempo revela un trance personal del poeta inglés, el cual estaba ciego, que aparece detonado en la imprecación interrogativa del verso sexto:

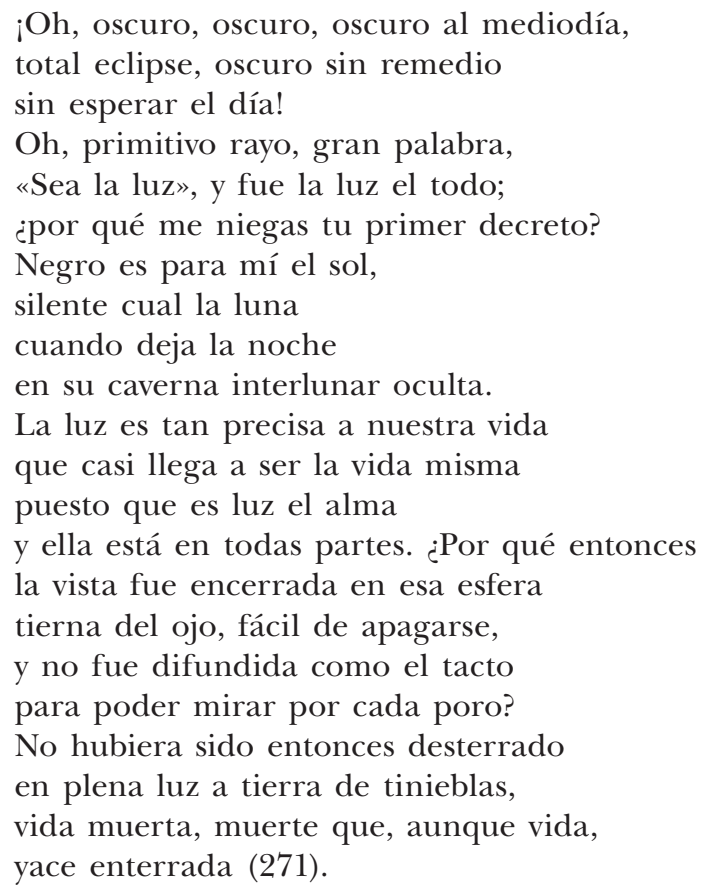

Dicho extracto proviene del inicio de la tragedia (se corresponde con los versos 80-101 del original) y ofrece una laudable simetría, según se coteja al comienzo del tramo donde destaca también la aminoración de la carga simbólica exacerbada típica del puritano inglés (por ejemplo «[...] the blaze of noon» es traducido como «al mediodía»): 
O dark, dark, amid the blaze of noon,

Irrecoverably dark, total Eclipse

Without all hope of day!

$O$ first created Beam, and thou great Word,

Let there be light, and light was over all;

Why am I thus bereav'd thy prime decree? (Milton, 1980: 445).

El segundo espécimen consta de veintiún versos, está también en versión monolingüe y se titula «El coro canta la muerte heroica de Sansón» (272). Así figura en la revista:

Pero él, aunque ciego de miradas,

despreciado y tenido por acabado totalmente,

con los ojos del alma iluminado,

atizó su gozosa virtud

con súbita llama bajo las cenizas,

y cual dragón de la tarde vino,

asaltador de las alcándaras

y nidos ordenados

como aldeanos pájaros; como un águila

sobre las cabezas arrojó su trueno sin nubes.

Así aquella virtud, ya dada por perdida,

que abatida y por tierra la creyeron

como el ave que de sí misma fue engendrada,

enclavada en los arábigos bosques,

que ni segundo ni tercero conoce

y que yació hace tiempo en holocausto,

de sus cenicientas entrañas alumbrada,

con más vigor renace y florece

cuando se creía más dormida,

y aunque su cuerpo muera sobrevive su fama,

ave secular con vidas por edades (272).

Proviene de la parte final del poema miltoniano (desde el verso 1687 hasta el 1707). Se trata de la última intervención del semicoro, aunque los traductores se refieran al coro. Expresa y celebra el triunfo de Sansón mediante la verbalización de la virtud, la imagen del águila, el ave fénix, su renacimiento y su fama. Todos estos elementos se hallan similarmente en los veintiún versos ingleses:

Semichor: But he thought blind of sight,

Despis'd and thought extinguish't quite,

With inward eyes illuminated

His fierie vertue rouz'd

From under ashes into sudden flame,

And as an ev'ning Dragon came, 
Assailant on the perched roosts,

And nests in order rang'd

Of tame villatic Fowl; but as an Eagle

His cloudless thunder bolted on this heads.

So virtue giv'n for lost,

Deprest, and overthrown, as seem'd,

Like that self-begott'n bird

In the Arabian woods embost,

That no second knows nor third,

And lay e're while a Holocaust,

From out her ashie womb now teem'd,

Revives, reflourishes, then vigorous most

When most unactive deem'd,

And though her body die, her fame survives,

A secular bird ages of lives (Milton, 1980: 478).

Hemos de señalar que ambos traductores publican en diciembre de 1949 un fragmento de la misma tragedia (desde el verso 710 hasta el 996) titulado «La escena entre Sansón y Dalila [...]» (Milton, 1949: 980-987). Se encuentra en una separata de la revista Escorial sexagésimo cuarta. El amplio fragmento está precedido de una introducción escrita por Charles David Ley (1949: 977-979) confirmando que se trata de una sinécdoque de la tragedia miltoniana que reverbera destellos autobiográficos (Sansón como elegido de Dios, la fortaleza, personaje casado varias veces).

\section{Un poema de Dylan Thomas traducido: «The Hand...»}

La revista séptima de la segunda época - fechada en abril-mayo de 1955 - contiene solamente una traducción de literatura extranjera, en este caso del inglés. Se trata del poema de Dylan Thomas (1914-1953) titulado «The Hand...» (301) cuya versión original se publica en Tiventy-Five Poems en 1936. El propio Ley (1981: 65) define a Thomas como «el poeta contemporáneo más enrevesado en lengua inglesa».

La tópica de la pieza gira en torno a la sinécdoque contenida en el sintagma nominal «The hand»y sus consecuencias (reiterado en los versos primero, noveno y undécimo; la misma estructura con el artículo indefinido en el verso décimo quinto y el sintagma en plural en el verso final), significando la capacidad decisiva de los poderosos para realizar masacres sobre la población.

El texto original se distribuye en cuatro estrofas de cuatro versos cada una —igual que el español— destacando a nivel prosódico la rima АВAB, así como el empleo de la anáfora que genera una isocronía tangible y un efecto reiterativo audible. El léxico es inteligible como regla general, excepto algunos términos como «goose [...]» o «locusts» que contrastan con la transparencia semántica general de la pieza, enfatizando mediante las dos imágenes 
animales el hecho de los asesinatos y las consecuencias de hambruna que generan las guerras.

Charles David Ley — que también titula a su pieza «La mano...»— traslada los dieciséis versos ingleses al español con la misma distribución estrófica y con el mismo número de versos que se cuentan en el texto original. Aplica una norma inicial (Toury, 1995: 56-57) de suma cercanía a la fuente sin engendrar desviaciones o interferencias reseñables, tal como evidencia la lectura de la primera estrofa:

The hand that signed a paper felled a city;

Five sovereign fingers taxed the breath,

Doubled the globe of dead and halved a country;

These five kings did a king to death.

La mano que firmó el papel taló una ciudad;

Cinco $[s i c]$ dedos soberanos impusieron tributo a la respiración,

duplicaron el globo de los muertos y midieron una nación;

estos cinco reyes dieron muerte a un rey (301).

Destaca el esquema prosódico mediante el empleo de patrones métricos más o menos regulares, cuya base métrica tiende a ser el alejandrino. Es evidente la adecuación férrea en todos los estratos lingüísticos y retóricos que genera Charles David Ley, quien incluso cuida de la rima al verterla en los dos versos centrales (en las siguientes estrofas la mantiene en otros dos versos). El traductor logra un inusitado tipo de equivalencia según demuestra, por ejemplo, la plasmación de las sinécdoques que representan las partes del cuerpo denotando la ilimitada y siniestra potestad del poderoso. Se aprecia una modulación en la adaptación de «[...] did a King to death» por «dieron muerte a un rey» cuya variación, al mudar el infinitivo a un verbo finito, no altera el sentido que Dylan Thomas confiere a su verso.

El modus operandi que el traductor aplica en la reescritura de la segunda estrofa también engendra un elevado grado de cercanía entre los versos articulando los mismos elementos léxicos y morfológicos mediante una distribución totalmente paralela que fundamenta el mantenimiento de matices tales como los tiempos verbales:

The mighty hand leads to a sloping shoulder,

The finger joints are cramped with chalk;

A goose's quill has put an end to murder

That put an end to talk.

La mano poderosa conduce a un hombro inclinado,

las falanges están calcinadas;

la pluma de ganso ha dado cabo del asesinato

que había dado cabo de la conversación (301). 
Charles David Ley ha comprimido el significado del atributo («[...] cramped with chalk») al nuevo atributo «calcinadas», evocando igualmente el resultado de un bombardeo o de unos disparos, lo cual luego se explicita mediante el sustantivo «asesinato». En este caso disuena la expresión verbal «dar cabo» - un calco del portugués- empleada por el traductor dos veces, gestando así un sentido exótico y extraño ante los ojos del lector español cuyo uso estimamos es consecuencia de la formación lingüística en portugués que tiene Charles David Ley.

La comparación de la siguiente estrofa también evidencia la cabal analogía entre ambas tiradas sintagmáticas y oracionales con sus respectivos componentes léxicos internos:

The hand that signed the treaty bred a fever,

And famine grew, and locusts came;

Great is the hand that holds dominion over

Man by a scribbled name.

La mano que firmó el tratado sembró una fiebre,

y el hambre creció, vinieron las langostas;

grande es la mano que tiene dominio sobre

el hombre por un nombre garabateado (301).

En este caso destaca de nuevo el esquema prosódico alejandrino generado por David Ley, por lo que hemos de argüir que la métrica ocupa una posición alta en las prioridades del traductor ${ }^{4}$. Solamente se aprecian dos inversiones que custodian y no oscurecen el significado original. Primero, en la oración coordinada «[...] and locusts came», que resulta «[...] vinieron langostas», la cual antepone el verbo al sujeto, si bien se trata de un hipérbaton de uso frecuente en la lengua española que en nada destiñe el sentido original. Segundo, la lógica inversión del adjetivo que modifica al «nombre» que en este caso naturaliza la sintaxis al estar situado tras el sustantivo.

Finalmente corroboramos la lealtad que venimos arguyendo, pues los cuatro últimos versos también trenzan una concordancia idéntica que ofrece los matices del texto inglés incólumes al nuevo receptor:

The five kings count the dead but do not soften

The crusted wound nor pat the brow;

A hand rules pity as a hand rules heaven;

Hands have no tears to flow.

4 En este sentido, Holmes (1970: 94) postula la importancia de la decisión del traductor respecto a la forma del verso, a la que se subordinan necesariamente las subsiguientes decisiones, lo cual refrenda Frank (1991: 122) en su estudio. 
Los cinco reyes cuentan los muertos, ni ablandan la herida encostrada ni acarician la frente; una mano reina en la compasión así como en el cielo; las manos no tienen lágrimas (301).

Estos versos de esta estrofa siguen un esquema métrico bien labrado, puesto que los dos primeros son dos alejandrinos perfectos, en tanto que el tercero consiste en un alejandrino y medio, es decir, un alejandrino entero más un hemistiquio, mientras que el cuarto verso es un octosílabo. Otros elementos sonoros se alzan en el «metapoema» (Holmes, 1970; Frank, 1990); por ejemplo, las aliteraciones de los fonemas nasales en los dos versos finales.

La única diferencia observada en esta estrofa final es la omisión de la unidad que cierra el poema «[...] to flow» cuya ausencia no resta sentido al verso meta puesto que su significado es sobreentendido gracias al verbo y al objeto directo precedentes «[...] no tienen lágrimas». Frente a estas diferencias nimias queremos acentuar la correlación literal entre ambas estrofas que dona al lector español un fiel poema sin restricciones estilísticas, semánticas ni morfosintácticas.

La inclusión de Dylan Thomas en la revista no es una anomalía, puesto que ya figura otro poema suyo en el número inicial de esta segunda temporada, entonces traducido por Marià Manent. De hecho, dicha revista cede nueve páginas para un monográfico de poesía inglesa y sustancia, por consiguiente, el interés renovado de los poetas de Cántico por la poesía internacional.

\section{Una autotraducción: «The Mosque Cathedral»: Hacia un análisis TRADUCTOLÓGICO}

El número octavo de la segunda época (junio-julio de 1955) contiene una traducción del inglés, concretamente de un poema escrito por el mismo Charles David Ley que es vertido al español por el propio escritor (322-323). Se trata de una entrega singular adjunta a unas páginas monográficas sobre poesía china (lo cual supone una exótica novedad en la importación de literatura extranjera en España). El doble ejercicio poético realizado por Charles David Ley se denomina autotraducción (Popovic, 1976: 19; Santoyo, 2005 y 2012; Recuenco Peñalver, 2011: 204).

El poema original aquí abordado se titula «The Mosque Cathedral» en tanto que el título del texto meta está acortado con un sustantivo menos con valor adjetival: «La Mezquita». El poema se compone de treinta versos distribuidos en seis estrofas desiguales que contienen tres, cinco, seis, seis de nuevo, ocho y un verso respectivamente. En la traducción figuran veintinueve versos al suprimirse uno perteneciente a la estrofa tercera. En el poema inglés, sobre el título, se aprecia el nombre del escritor en letra grande mayúscula. 
Tras la traducción, en la página derecha consta entre paréntesis el mismo nombre «(Trad. de Ch. D. Ley).» en letra pequeña, abreviada y cursiva:

Pause in the Temple to our God; dream on

Of civilizations which have been lost and won,

But here the whole is harmonized.

Water flowing and gurglin $[s i c]$ under the bridges!

Water lapping lusciously through the little bronze stag

While men remembered Princes dead in the hour of return!

Alah save you, o Princes, from eternal flames!

So said the men of old Córdoba.

But it was not Alah who could dwell here

In this great Christian Mosque. The East stands firm,

New rooted in the faith of Christendom.

The forest of mankind finds revelation,

Bearing in its central womb flower of Europe,

Finally redeemed by the only monarch

Who was something approaching a King of Europe.

Under the deep sky sound the myriad bells.

Beauty and flowers are everywhere, and wine.

Here in the Mosque-Cathedral the Virgin watches

And Christ's Passion is framed in gracious gold

As an eternal memory of the blending

Of all civilization into one religion.

The very air is joyful in the Cathedral.

Prayer like a seedling floats among the forests.

If I could speak my heart upon this page

It would spell nothing till the end of time.

Life is a host, a sheaf of threads entwined,

Of criss-cross thoughts and feelings which explain each other.

If not, I could weary time itself to explain

God's Majesty revealed in this two-fold flower.

Yet oh! those endless avenues of sweet arches! (322-333).

La primera estrofa objetiva las raíces interculturales de la ciudad califal señalizadas en el propio templo catedralicio. La segunda estrofa celebra el agua cuyo río y fuentes caracterizan a la capital, así como al cervatillo — que es un emblema de la ciudad omeya Medina Azahara de Al-Ándalus (en el poema definida como «la vieja Córdoba»), construida por Abderramán III-, rememorando también las consecuencias de la guerra que terminó con el Califato de Córdoba. La tercera alude a la mezcolanza de religiones que representa la Mezquita. La estrofa cuarta, ya centrada en el momento de escritura del poema hacia mitad de la década de los 50, incluye rasgos caracterológicos del monumento y de su entorno como son el toque de las campanas, las flores y el vino subrayando la definición cristiana y católica del 
recinto a través de las referencias a la Virgen, a la Pasión de Cristo y a la fe de los creyentes. La estrofa siguiente, la que más versos contiene, refleja el regocijo que siente el sujeto lírico contemplando el rezo en el interior de la Catedral, tratando de definir la vida y destacando la imagen majestuosa de Dios. Finalmente, un solo verso corona la serie valorando con una admiración las calles de arcos que armonizan y ornamentan el interior del recinto.

El poema tematiza la Mezquita-Catedral recreando - en el primer tramo- la génesis del monumento cristiano y realzando el carácter católico del lugar en la segunda parte de la pieza. El sujeto lírico, el poeta pensamos, se muestra gozosamente subyugado ante la evocadora belleza de la Catedral, lo cual a nivel sintáctico se materializa mediante los cinco versos escritos con signos de admiración (el último verso inglés, verbigracia, contiene dos exclamaciones: «Yes oh! Those endless avenues of sweet arches!»). Ley aúna en su universo textual referencias a civilizaciones pasadas, a elementos naturales a través del agua, las flores o el aire, así como a otros parámetros característicos de la ciudad como son los puentes, el cervatillo de bronce o el vino.

El texto español mantiene la mayoría de los elementos primigenios de la composición, aunque se aprecian algunas mutaciones que seguidamente vamos a tratar. He aquí la traducción:

Detente en el Templo de nuestro Dios; sigue soñando en civilizaciones perdidas y ganadas, ahora que aquí todo se armoniza.

¡El agua que fluye y chapotea bajo los puentes!

¡El agua que murmuraba gozosa por el cervatillo de bronce

apenas los hombres se acordaban de los príncipes muertos a su regreso!

¡Alá os libre, oh príncipes, de las llamas eternas!

Tal decían los hombres de la vieja Córdoba.

No fue Alá quien aquí morar pudo

en la mezquita cristiana. Se mantiene el Oriente

con hondas raíces nuevas en la fe de la Cristiandad,

llevando en su útero central la flor de Europa

finalmente redimida por el único monarca

que fue algo así como Rey de Europa.

Suena la miríada de campanas bajo el hondo cielo.

La belleza, las flores y el vino están en todas partes.

Aquí en la Mezquita la Virgen vigila,

y la Pasión de Cristo en su marco de oro gracioso

es una memoria eterna de cómo se funde

toda la civilización en una fe única.

El mismo aire es alegre en la catedral

El rezo, cual vilano, flota por las florestas.

Si yo pudiera en esta página expresar mi corazón 
él no diría nada hasta el final de los tiempos.

La vida es una hueste, una gavilla e hilos entretejidos, de ideas y sentimientos cruzados que mutuamente se explican.

Si no, yo cansaría al propio tiempo intentando explicar

la Majestad de Dios en esta doble flor revelada.

Mas, ah, esas avenidas sin fin de dulces $\operatorname{arcos}(323)$.

Charles David Ley cuida la forma del verso gracias a un ritmo creado a través de patrones métricos regulares como el empleo del alejandrino en algunos versos, la anáfora y la aliteración de determinados fonemas. Dicho esto, el primer elemento que hemos de analizar es el título cuyo sintagma nominal inglés compuesto por dos sustantivos tras el artículo determinado («The Mosque Cathedral») emana en el texto meta acortado mediante un nombre solamente tras el artículo determinado. Se infiere que la carga semántica se mantiene, sin embargo surge un asunto de calado histórico porque el título original recoge el pasado islámico del edificio, al tiempo que incorpora la otra referencia a su carácter cristiano tras la Reconquista, en 1238, a manos de Fernando III de Castilla que destina el monumento para la liturgia cristiana, generando así el cambio de la denominación Mezquita por Catedral. Por ello, el nuevo título pergeñado deturpa a la cabecera de este segundo sentido necesario.

La primera estrofa mantiene los elementos léxicos, morfológicos y semánticos en ambos poemas, desde los dos verbos imperativos que abren la serie abruptamente, sus complementos hasta la postmodificación aportada por «[...] which have been lost and won» que emerge como «[...] perdidas y ganadas». En este caso Ley aplica una transposición en la clase de la uni$\operatorname{dad}^{5}$ al plantear la oración de relativo — que contiene dos verbos principales coordinados - como dos participios también coordinados mediante la conjunción. El traductor reduce las oraciones de relativo mediante un participio. El verso tercero se articula de forma similar exceptuando el cambio de la mutación de la conjunción adversativa inglesa por un adverbio temporal que denota inmediatez, el cual, unido al significado de «aquí», enfatiza el hic et nunc del poema: «ahora que aquí todo se armoniza», «But here the whole is harmonized».

La traducción de la segunda estrofa destaca por su fidelidad anatómica, ya que conserva las tres exclamativas originales distribuidas incluso en los

5 Para abordar las estrategias de traducción aplicadas en el análisis se ha tenido en cuenta el estudio de los canadienses Vinay y Dalbernet (1977: 266-289), que explican una serie de procedimientos necesarios en la traducción oblicua (Vázquez Ayora, 1977: 266). También se han considerado los mencionados trabajos de Holmes (1970: 97) y Frank (1990: 116-117), cuyas aportaciones son fructíferas para el análisis de poesía traducida. 
mismos versos; además mantiene intactos los sintagmas de cada línea de manera correlativa en ambos poemas. De esta forma, el verso primero («Water flowing and gurglin[g] under the bridges!») es trasladado como «iEl agua que fluye y chapotea bajo los puentes!». Si en la estrofa anterior se aprecia un acortamiento de las oraciones de relativo, en esta se observa la estrategia contraria, a saber, los dos gerundios con función de postmodificadores del sustantivo son traducidos expandidos como oraciones de relativo, conservando también la conjunción coordinativa. El traductor aplica otra transposición en la estructura de la unidad al cambiar dos gerundios por dos cláusulas de relativo. Después, el complemento circunstancial de lugar está reescrito con total apego al original.

El segundo verso de esta segunda estrofa también presenta una simetría notable con una diferencia similar a la antedicha, el cambio de «lapping» por «que murmuraba», añadiendo además un aspecto en la transformación temporal al traducir el gerundio como pretérito imperfecto. El verso tercero presenta una sutil metamorfosis semántica digna de registrar: «While men remembered Princes dead in the hour of return!»: «apenas los hombres se acordaban de los príncipes muertos a su regreso!». El cambio de «While» por «apenas» - conservando también su sentido según una de sus acepciones- agrega un nuevo matiz al texto meta al añadir la idea de dificultad. Los siguientes elementos quedan simétricos, apreciándose solamente una modulación en el complemento circunstancial de tiempo («[...] in the hour of return») al final del verso al omitir el sustantivo «hour» («a su regreso») y al tornar el núcleo del genitivo por un núcleo del sintagma preposicional con valor de lugar. Esta leve alteración no destiñe, empero, la alusión semántica a tiempos bélicos en Al-Ándalus que late en la fuente. Los dos últimos versos están reescritos ad pedem litterae mediante los elementos léxicos, morfológicos y las funciones sintácticas de los mismos, destacando la conservación del vocativo original e incluso el orden sintagmático.

La estrofa tercera tematiza el cambio religioso y cultural del monumento, comenzando por una oración coordinada adversativa que contiene a su vez una oración copulativa y una oración de relativo referida al atributo "Alah». Ley mantiene la misma sintaxis en el poema español, así como los verbos en pasado. Sin embargo se aprecian algunas variaciones leves tales como la omisión de la conjunción adverbial inicial, cuyo sentido se halla recogido (y compensado así en parte) en la partícula negativa que en el verso meta aparece en primer término gracias al sujeto elíptico de la misma («it»), desproveyendo al nuevo poema de la vehemencia adversativa original. La oración de relativo presenta un hipérbaton que adelanta el adverbio de lugar y pospone el verbo principal («[...] who could dwell here», «[...] quien aquí morar pudo»), consiguiendo un efecto prosódico en la aliteración del sonido 
al duplicar el fonema oclusivo velar de manera consecutiva, pero preservando el significado íntegro.

La estrofa cuarta se acerca al momento de la escritura recreando detalles relevantes mediante el presente simple, que es trasladado al texto meta fielmente en presente de indicativo. El primer verso («Under the deep sky sound the myriad bells»), que se articula mediante una esticomitia, se plantea simétrico como «Suena la miríada de campanas bajo el hondo cielo», posponiendo el complemento circunstancial de lugar al tramo final del mismo y manteniendo todos los elementos internos con la única variación del adjetivo «myriad» —que en inglés también tiene valor de sustantivo- por el nombre «miríada» ofreciendo, de nuevo, la semántica de la plántula completa. El verso tercero - que incorpora la referencia cristiana a la Virgen- ofrece al lector español los mismos elementos lexicales en el orden original mutando el sintagma nominal «the Mosque-Cathedral» por «la Mezquita» —una especie de sinécdoque - restando el énfasis cristiano que aporta el significante «Cathedral» pero ofreciendo prácticamente todo el sentido pleno al receptor que esté familiarizado con el empleo de ambos términos de modo unívoco en el siglo xx, si exceptuamos las connotaciones antedichas a propósito del título del poema.

Si antes aparecía un elemento mariano, ahora (en el verso cuarto de la estrofa cuarta) aflora una referencia al mismo Jesucristo, figura central del cristianismo, con bastante apego al original: "And Christ's Passion is framed in gracious gold», "y la Pasión de Cristo en su marco de oro gracioso». La única mutación que se aprecia es la transposición del grupo verbal «is framed» al grupo nominal «en su marco», detrayendo el valor oracional del verso sin desproveerlo de su significado. El siguiente ( As an eternal memory of the blending», «es una memoria eterna de cómo se funde») presenta un transvase a nivel tropológico, puesto que elimina el símil que introduce «As», si bien genera el mismo efecto a través del verbo copulativo y del atributo. A continuación expande el complemento del nombre en ambos poemas con algún cambio nimio que no trastoca el significado original (del nombre «blending» al grupo verbal «se funde» junto a la adición del adverbio interrogativo «cómo»). El verso final de la estrofa (aunque presenta un cambio de grupo preposicional a grupo nominal al prescindir de «of») conserva los componentes elementales de manera correlativa, observándose una modulación de concreto a abstracto al traducir «religión» por «fe única», realzando así la creencia y la convicción humana en unos valores concretos mediante el sustantivo «fe». Además, es destacable la amplificación aportada por la adición del adjetivo «única», que realza la exclusividad del rito cristiano profesado en la Catedral, a la vez que magnifica la cualidad devocional. 
La estrofa quinta prosigue con la fidelidad señalada, a excepción de dos transformaciones. Los dos primeros versos españoles, dos esticomitias, albergan los mismos elementos léxicos e incluso el mismo orden que en el inglés. Destaca incluso el mantenimiento de las figuras retóricas de la personificación del aire (al que se le atribuyen cualidades humanas) y del símil el cual está engendrado en el nuevo poema a modo de aposición, mediante dos comas que no constan en el original. El verso tercero estructura la prótasis de una oración condicional («If I could speak my heart upon this page», «Si yo pudiera en esta página expresar mi corazón»), en tanto que la apódosis se extiende en el verso cuarto («It would spell nothing till the end of time», él no diría nada hasta el final de los tiempos»). Se distingue un cambio en los sintagmas de la subordinada mediante un hipérbaton que intercala el complemento circunstancial de lugar entre el verbo auxiliar y el verbo principal, mientras que en la principal descuella una similitud en lo que atañe a los sintagmas, a las funciones sintácticas y a la semántica, siendo simplemente digno de mención el cambio del sujeto neutro pronominal de la fuente («It») por el sujeto de tercera persona masculino («él»), designando así al sustantivo antecedente («corazón») con cualidades humanas mediante una especie de prosopopeya.

Entre los versos séptimo y octavo se descubre un encabalgamiento abrupto que separa al verbo («[...] to explain», «[...] «explicar») de su complemento directo («God's Majesty [...], «la Majestad de Dios» [...]), el cual emerge en el texto español de la misma forma. La traducción acentúa una transposición al modificar la oración final («[...] to explain») por un complemento circunstancial de modo generado a través del gerundio «[...] intentando explicar» al que el traductor añade el matiz de procurar o de pretender aportado en el citado gerundio. El verso octavo, cuyas funciones sintácticas y elementos sintagmáticos se conservan, presenta un cambio de orden en el participio que introduce una oración adjetiva («[...] revealed in this two-fold flower», «[...] en esta doble flor revelada»), originando un hipérbaton en la poesía española al colocar «revelada» en último término.

Finalmente destaca el verso que corona el poema cuyos grupos de palabras son idénticos («Yet oh! Those endless avenues of sweet arches!», «Mas, ah, esas avenidas sin fin de dulces arcos»). Solamente hay que especificar la aminoración en la expresión del asombro que sí sobresale en el texto fuente mediante los dos signos de admiración, los cuales no constan en el texto meta; sin embargo, se mantiene la interjección de exclamación («oh» que es traducida como «ah»). Además, ambos versos articulan y transmiten el efecto de la prosopopeya que produce el adjetivo «sweet» o «dulces» aplicado a los «arcos» de la Catedral.

A la luz de lo antedicho, se deduce que Charles David Ley genera una autotraducción «naturalizante», si aplicamos la tríada clasificatoria 
conceptualizada por Oustinoff (2001), porque en el texto meta destacan las normas lingüísticas de la lengua término sin hallar elementos disonantes o interferencias de la gramática o de la semántica generada en el poema inglés. Por otra parte, aplicando los postulados de Grutman (2009: 125), deducimos que la reescritura de Ley es una autotraducción simultánea porque ambos poemas emanan de manera diacrónica. El escritor —utilizamos la teoría de Santoyo (2013) - aplica a ambos textos una relación dinámica prevaleciendo su interacción constante que ocasiona en algunos casos modificaciones aceptables.

\section{Concluusión}

Las colaboraciones de Charles David Ley en la revista Cántico se dividen en tres grupos. En primer lugar, destacan poemas de autoría propia, como evidencian las composiciones «Meditation»y «The Mosque Cathedral». En segundo lugar, se distinguen sus traducciones, dos fragmentos de la tragedia inglesa Samson Agonistes, en coautoría con García Cano, y otra de una pieza de Dylan Thomas titulada «The Hand...». Finalmente se vislumbra una tercera modalidad: la autotraducción, porque el propio filólogo inglés compone el texto fuente «The Mosque Cathedral» y lo reescribe en español bajo el título «La Mezquita», aunando así su faceta y su formación bilingües.

En estas «Hojas de poesía» (19) reluce la presencia del filólogo londinense a través de sus colaboraciones fragmentarias que emanan dispersas en el tiempo. Su inclusión denota la consideración y el valor que el literato tiene para los directores de la revista, ofreciendo un consiguiente enriquecimiento de la misma gracias a sus aportaciones. La presencia de Charles David Ley en las páginas de Cántico es una forma de prestigiar la altura intelectual de la publicación, porque se trata de un escritor académicamente bien formado, con experiencia docente en dos países y bien relacionado en los círculos españoles de poesía.

\section{Bibliografía}

Aleixandre, V. (2007): "Carta a los fundadores de Cántico». En: Cántico. Hojas de Poesía. Córdoba 1947-1957. Córdoba, Junta de Andalucía-Diputación de CórdobaFundación Cajasur, págs. 35-36.

Blanco Outón, C. (1994): «La poesía inglesa y alemana en la Revista Cántico». En Merino Álvarez, R. et al. (eds.): Transvases culturales: Literatura, cine y traducción. Vitoria, Universidad del País Vasco, págs. 95-103.

Brenan, G. (1952): La faz actual de España. M. Amilibia (trad.). Buenos Aires, Losada. Castro, R. de (1964): Poems. C.D. Ley (trad.). Madrid, Ministry of Foreign Affairs.

Grutman, R. (2009): «La autotraducción en la galaxia de las lenguas». Quaderns: revista de traducción, 16, págs. 123-134. 
Holmes, J.S. (1970): «Forms of Verse Translation and the Translation of Verse Form». En Holmes, J.S. y Popovič, A. (eds.): The Nature of Translation. The Hague, Mouton, págs. 91-105.

Frank, A.P. (1991): «Translating and Translated Poetry: the Producer's and the Historian's Perspectives». En van Leuven-Zwart, K.M. y Naaijkens, T. (eds.): Translation Studies: The State of the Art. Proceedings of the First James S. Holmes Symposium on Translation Studies. Amsterdam-Atlanta, Rodopi, págs. 115-140.

Ley, C.D. (1947): Portuguese Voyages 1498-1663. London, J.M. Dent \& Sons Ltd.

- (1949): «Sansón Agonistes, de John Milton». En: Sansón Agonistes, de John Milton. Separata de la revista Escorial. Madrid, págs. 977-979.

- (1951): La moderna poesía portuguesa. Santander, Imprenta Bedia.

- (1952): Poemas para España. Santander, Librería Moderna.

- (1962): Spanish Poetry Since 1939. Washington, The Catholic University of America Press.

- (1964): Bulls and Bullfighting. Barcelona, Editorial Noguer.

- (1967): «El amor y la amada en la poesía contemporánea de España». En: Actas del II Congreso de la Asociación Internacional de Hispanistas celebrado en Nijmegen del 20 al 25 de agosto de 1965. Nijmejen, AIH-Instituto Español Univ. Nimega, págs. 377-385.

- (1970): «Influencia de Pablo Neruda y de otros poetas hispanoamericanos en la moderna poesía de España». En: Actas del III Congreso de la Asociación Internacional de Hispanistas celebrado en México D.F. del 26-31 de agosto 1968. México, AIH-El Colegio de México, págs. 543-552.

- (1977): «Lope de Vega y los conceptos teatrales de Aristóteles». En: Actas del Quinto Congreso de la Asociación Internacional de Hispanistas celebrado en Bordeaux del 2 al 8 de septiembre de 1974. Bordeaux, Instituto de Estudios Ibéricos e Iberoamericanos (Univ. Bourdeaux III), págs. 579-585.

- (1981): La Costanilla de los diablos (Memorias literarias 1943-1952). Madrid, José Esteban.

- (1988): «El Café Gijón y la "juventud creadora”. En: Tudela, M. et al.: Café Gijón. 100 años de historia. Madrid, Kaydeda, págs. 183-188.

Mainer, J.C. (2005): «La vuelta de Garcilaso». Revista de Libros, 103-104, págs. 1-4.

Martín Puya, A.I. y Moreno Díaz M.C. (2013): Los años de Cántico. Córdoba, Ayuntamiento de Córdoba-Universidad de Córdoba.

Milton, J. (1949): Sansón Agonistes de John Milton. J. García Nieto y C.D. Ley (trads.). Separata de la revista Escorial, Madrid, págs. 977-987.

- (1980): The Complete Poems. G. Campbell (ed.). London, J.M. Dent \& Sons Ltd.

Ortega Spottorno, J. (1996): «Charles David Ley, hispanista». El País, 15 de octubre.

Oustinoff, M. (2001): Bilinguisme d'écriture et auto-traduction. Julien Green, Samuel Beckett, Vladimir Nabokov. Paris, L'Harmattan.

Popovic, A. (1976): Dictionary for the Analysis of Literary Translation. Edmonton, The University of Alberta. 
Recuenco Peñalver, M. (2011): «Más allá de la traducción: la autotraducción». TRANS, 15, págs. 103-208.

Santoyo, J.C. (2005): «Autotraducciones: Una perspectiva histórica». Meta: journal des traducteurs / Meta: Translators' Journal, 50.3, págs. 858-867.

- (2012): «La autotraducción en la Edad Media». En Rubio, M. et al. (eds.): Autotraduzione: Teoría ed esempi fra Ialia e Spagna (e oltre). Milano, Del, págs. 63-76.

- (2013): «On Mirrors, Dynamics and Self-Translations». En Cordingley, A. (ed.): Self-Translation: Brokering Originality in Hybrid Culture. London, Bloomsbury, págs. 27-38.

Torralbo Caballero, J.D. (2018a): «La 'afín universalidad' de la revista Cántico: Presentación y estudio de los transvases internacionales». Impossibilia, 16, págs. 136-171.

- (2018b): «Literatura inglesa en las hojas de Cántico». Monteagudo, 23, págs. 169-186.

Toury, G. (1995): Descriptive Translation Studies and Beyond. Amsterdam, John Benjamins.

VÁzQuez Ayora, G. (1977): Introducción a la traductología. Georgetown, Georgetown University Press.

Vinay, J.P. y Dalbernet J. (1977): Stylistique comparée du français et de l'anglais. Montrèal, Beauchemin. 